\title{
Reopening an Abandoned Underground Mine - 3D Digital Mine Inventory Model from Historical Data and Rapid Laser Scanning
}

\author{
T. Makkonen ${ }^{a}$, R. Heikkilä ${ }^{a}$, J. Jylänki ${ }^{b}$, S.J. Fraser ${ }^{c}$ \\ ${ }^{a}$ Construction Technology Research Center, University of Oulu, Finland \\ ${ }^{b}$ Otanmäki Mine Oy, Finland \\ ${ }^{\mathrm{c}}$ CSIRO Mineral Resources Flagship, Queensland Centre for Advanced Technologies, Australia \\ E-mail: Tomi.Makkonen@oulu.fi, Rauno.Heikkila@oulu.fi,jjylanki@vuorokas.fi, Stephen.Fraser@csiro.au
}

\begin{abstract}
-
The decision to reopen a mine abandoned for $\mathbf{3 0}$ years is going to be complex because a significant financial commitment is going to depend on a reevaluation of both the remaining mineral resource and the surviving mine infrastructure. Historical pre-digital records will need to be assessed and new data acquired both to prove up an ore reserve and to assess the status of existing mine development and infrastructure. We describe how historic mining data were collected and compiled on the mine infrastructure (tunnels, buildings) and how mineral resource data were prepared and transferred into a 3D digital mine inventory for the Otanmäki Mine in Finland. We also demonstrate the applicability of rapid handheld laser scanning for simultaneous localization and mapping to supplement the available mine plans. Point-cloud laser scans were collected in the hoisting tower and evacuation shelter.
\end{abstract}

Keywords -

mine; reopening mine; BIM; historical data, point-cloud laser scans

\section{Introduction}

Reopening a closed mine typically requires a substantial capital investment and the data needed to support such decisions [1] needs to be collected and measured precisely. Models of the infrastructure and mineral resource are two important factors (see Figure 1), because both are assets that can be given a value. For example, we estimate that the price of one meter of tunnel development is 1000 - 2000 euros; and drill holes are 100 euros per meter. Assessing the value of existing assets is a significant problem, when financing the reopening of a mine [2-4].

In Finland, a new public specification for infrastructure (roads, railways, fairways and bridges) called YIV2014 [5] (currently still draft) has been published; and key clients are already demanding its use. The YIV2014 specification determines the minimum requirements for the starting situation, i.e. initial data model needed. Special attention and guidelines have been set for the data acquisition methods used, how the data are documented, and even how the required folders and files are named. Attention has also been given to the coordinate systems for spatial data, data transfer formats and the accuracy of different data types. The main principle is that all identified key information and data should be modelled to a specification. Special production model is to be created for automated machine control purposes.

In the Finnish building sector, the COBIM2012 specification [6] details the acceptable standards on how to digitally model the base information for a building construction. The modelling of the site and existing building can be based on measurements, inventories and investigations performed on site. The information is supplemented with existing drawings and other documents. The site model has to be at least a three dimensional surface model. Other site elements are modelled to an agreed accuracy. The special layer system used in the Inventory Model has to be documented to BIM specifications [6] if the modelling software has no layers. The information should be organized in a logical way according to the building elements, and again, documented to the BIM specification. To avoid a common problem in most design software, the coordinate system is defined so that the datum point is situated near the building. Laser 
scanning measurements can be used to capture awkward surfaces like roofs and walls, or by other 3D survey methods like total station or photogrammetric systems. Tolerance of $10 \mathrm{~mm}$ has been set for the inventory measurements of corner points of building elements, 25 $\mathrm{mm}$ for surfaces like walls and floors, and $50 \mathrm{~mm}$ for old irregular structures such as roof structures.

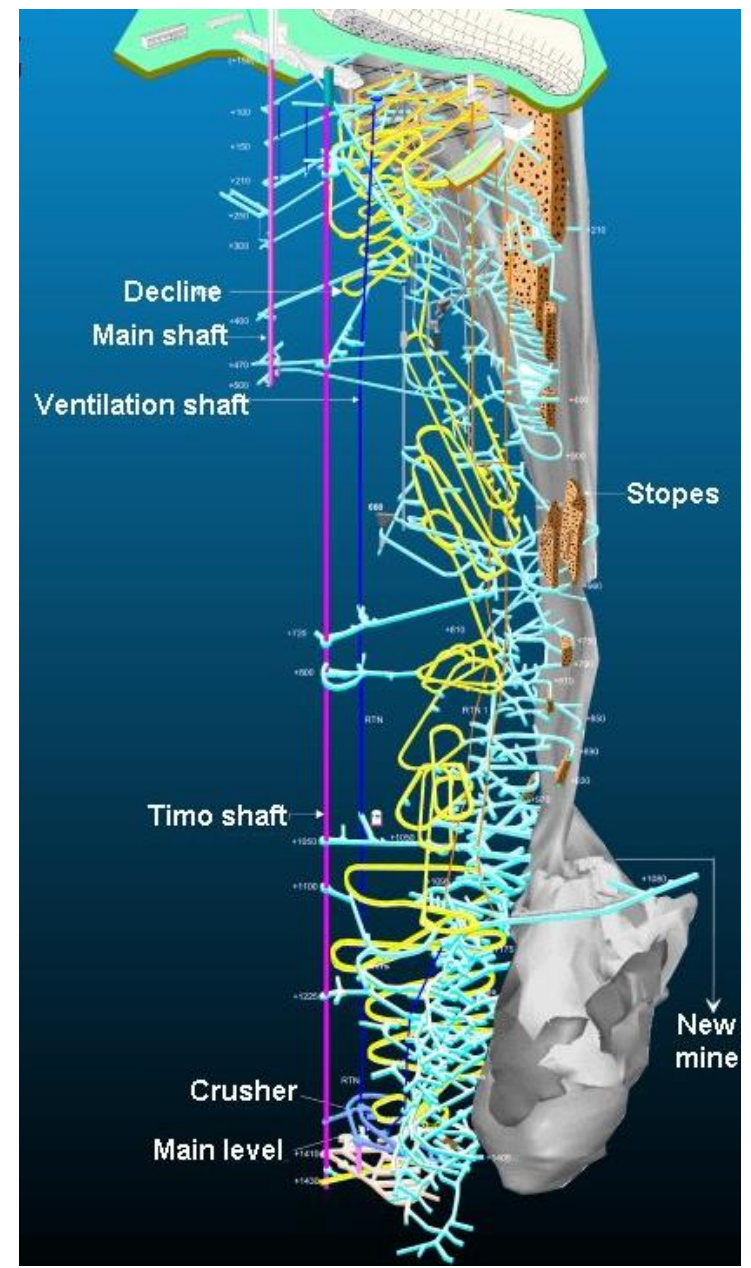

Figure 1. Part of the "digital" inventory model of Pyhäsalmi Mine (Source: Pyhäsalmi Mine)

Geological data have been acquired at the Otanmäki mine since its discovery in 1937, and even more mining-related data since operations began in 1953. After 48 years of operation, the mine closed in 1985. Most of the historical data exists in typed reports, memos, handwritten logs or on hand-drafted maps. All of which require entry into digital systems.

In this paper we detail how we processed historical mine information into a digital inventory model, specifically information about the infrastructure and mineral resource. We also present measurements from a hand held laser scanner that was used to rapidly scan the internal form of a complex hoisting tower for the infrastructure model and an evacuation shelter, built to resemble a mine tunnel. The tunnels at the Otanmäki mine are full of water, so they will present an interesting measurement target once drained.

\section{Constructing the digital mine inventory model}

The digital mine model was constructed mainly by digitizing and including historical data, created from when the mine was operational. The main sources of data were the old 2D maps, plans, cross-sections and drill logs for exploration diamond holes with mineralized intersections and grades. Most of the other data sources are presented in the Table 1.

The mine inventory model constructed solely from historical data is not a full presentation of the current situation because of post-mining collapse and flooding. Consequently, we used a rapid hand held laser scanning system to improve the infrastructure model.

Table 1. Historical data sources

\begin{tabular}{ll}
\hline Type of information & Format \\
\hline Tunnel maps & 2D picture hand-drawn \\
$\begin{array}{l}\text { Bore hole maps } \\
\text { Bore hole susceptibility } \\
\text { measurements }\end{array}$ & $\begin{array}{l}\text { 2D picture hand-drawn } \\
\text { texilled hole maps }\end{array}$ \\
$\begin{array}{l}\text { Drilled hole log books } \\
\text { Ground level infra }\end{array}$ & text \\
Geological models & 2D picture hand-drawn \\
\hline
\end{tabular}

The hand drawn 2D tunnel maps were first scanned and then imported to QGIS [7], an open source geographic information system, for viewing, editing and analysis. Larger maps were created by stitching them together (Figure 5); for example, a larger mosaic map was created for each mine level.

We georeferenced the scanned maps by selecting readily identifiable features and manually setting their coordinates in QGIS. The mine maps were marked in the KKJ coordinate system [8] (Finland Uniform Coordinate System), the same coordinate system for the proposed future Otanmäki Mine redevelopment.

Referenced maps were then digitized by following the tunnel wall lines. These newly digitized maps were then completed in a mine-planning program (Surpac) to include height (z-axis) information from vertical cross section 2D maps, and finally the shape of the tunnel was approximated from drawings. In unclear situations, general knowledge and know-how about tunnel design and shapes were used, as well as knowledge from people who had visited the Otanmäki Mine when operational. After these steps, a full 3D tunnel map was 
ready for use and analysis.

Plans of other infrastructure, like buildings and roads (e.g. the hoisting tower) needed to undergo similar 2D to 3D work flow. However, because these are easier to access and measure, laser scanning is a tool one can use to achieve more up to date model representation..

The applicability of rapid point cloud generation using the hand held laser scanner ZEB1 [9], [10] for scanning complex infra buildings was assessed. Two tests were conducted: the first in an old evacuation shelter (Figure 13); and the second, in the hoisting tower, which has 8 floors, some 55 meters above ground level and a small basement (Figure 7). The hand held laser scanner uses simultaneous location and mapping [11], thus it will build the 3D map as the measurements are taken, so that no georeferencing is needed.

The hoisting tower is full of old equipment, including three elevators. The total depth of the hoisting shaft is approximately 675 meters and the diameters of the pulleys are ca. 5 meters. Most of the hoisting machinery equipment is located in the top floor (see Figure 10).

We estimated if a conventional standing tripod laser scanner was used, due to multiple scanning locations needed, and the difficulty to create reference points in a cramped tall tower, scanning the tower would take approximately two days. Here we study the time taken to scan the tower with the handheld laser scanner, as well as to visually assess the coherence of the point cloud. An accuracy analysis is done later.

Our second handheld laser scanning target was an old evacuation shelter, with a length over one hundred meters (Figure 15)

For use in our inventory model, point clouds were converted to triangulated mesh. The tool we choose was coded by Kazhdan [12] and uses Screened Poisson Surface Reconstruction. This code has two advantages: a) It copes with noisy data; and b) It can process huge point clouds.

Plans for future handheld laser scanning measurements include the tunnels, stopes, shafts and various open spaces constructed during the operational years. As noted the tunnel network is modeled now based on digitization of the old 2D maps, but we need to build more detailed knowledge that reflects the current situation as the evaluation proceeds. All the aforementioned underground spaces are currently filled with water. Dewatering of the mine is planned during the coming 1-2 years. The total amount of water in the Otanmäki mine is ca. 7 million $\mathrm{m}^{3}$. In the future we plan extend the inventory model using wide range of measurement methods, including remote operated laser scanning and video surveillance.

According to Glacken [13] mineral resource estimation for the inventory model is only possible after the estimator is sure about the soundness of the data. He also adds that data used for both estimation and geological interpretation must have integrity and robustness; and the geological data must be sufficiently complete. Standards exist for reporting exploration, mineral resource and ore reserve results $[14,15]$; and we endorse their use.

The geological block model is the first attempt to represent the previous resource for mining purposes.

The most important parameters in Otanmäki Mine block model are the assay grades for the extracted metals, iron, vanadium and titanium. Mining blocks have a 3D location in Otanmäki mine coordinate system. As previously mentioned, northings and eastings are in KKJ system; and mine elevations are calculated against a reference point situated on the highest hill in the mine region. The elevation reference point is 189 metres amsl.

A huge amount of data was collected during the operational years of the mine. These data include about $300 \mathrm{~km}$ of exploration diamond drill logs and data (core retrieved) with assays for mineralized intersections. A secondary source of information is approximately 600 $\mathrm{km}$ of borehole geophysical $\operatorname{logs}$ of magnetic susceptibility measurements (Figure 2) that were used to estimate mineralization grades. These susceptibility grade estimates were quite accurate as exploration diamond drill holes were used to calibrate the measurements. Open boreholes were mostly used between the exploration cored holes because they were cheaper and faster to drill. Unfortunately most of the magnetic susceptibility results are still missing, possibly permanently.

The drilling database is the essential element of our 3D model. Old drilling log books and 2D hand-drawn sketches (Figure 3) show information like: 1. Collar coordinates of drill holes in 3D 2. Direction and angle of drilling 3. Length of the hole 4. Assay grades per meter. The drilling database of the Otanmäki mine is currently under construction. Part of the drilling database has been already compiled and these data have been used to construct the preliminary 3D mineralization model, shown in Figure 17, (along with the 3D-view of the tunnel and 2 main hoisting shafts).

Rock and mineralization styles are shown on 2D maps, which are coded with different colours (see Figure 6). Currently only different mineralization styles have been digitized and imported to block modelling software. Later, different rock types will be digitized and added to the modelling software. 


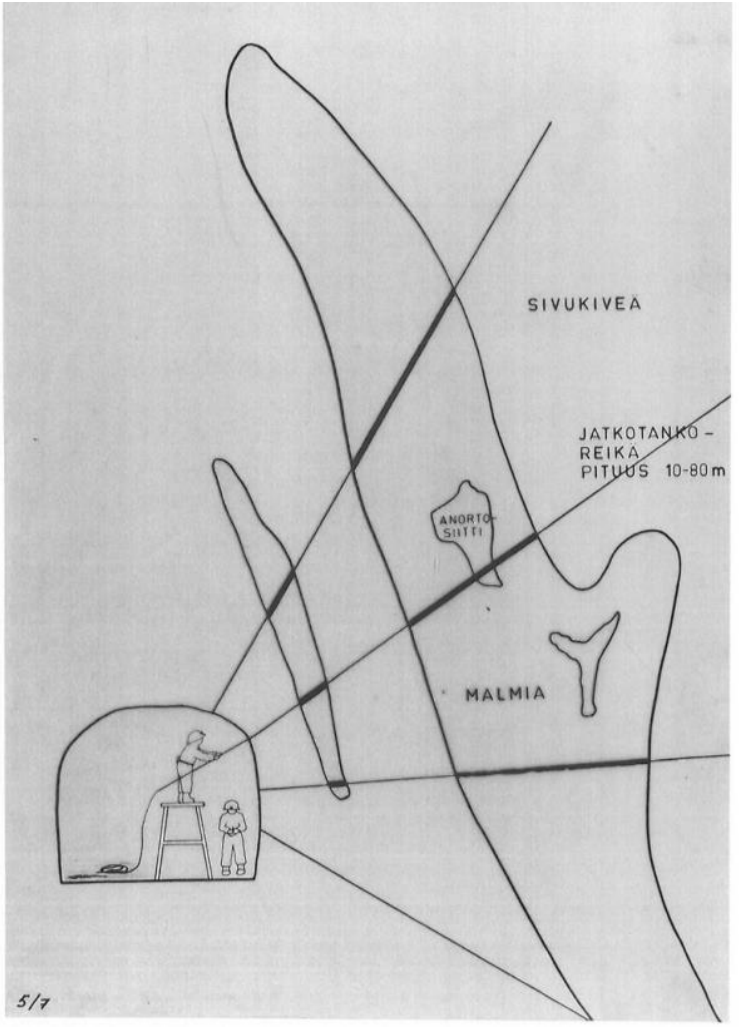

Figure 2. Historical 2D figure - Cross section of an ore body and tunnel in Otanmäki Mine. Measuring of susceptibility along bore holes

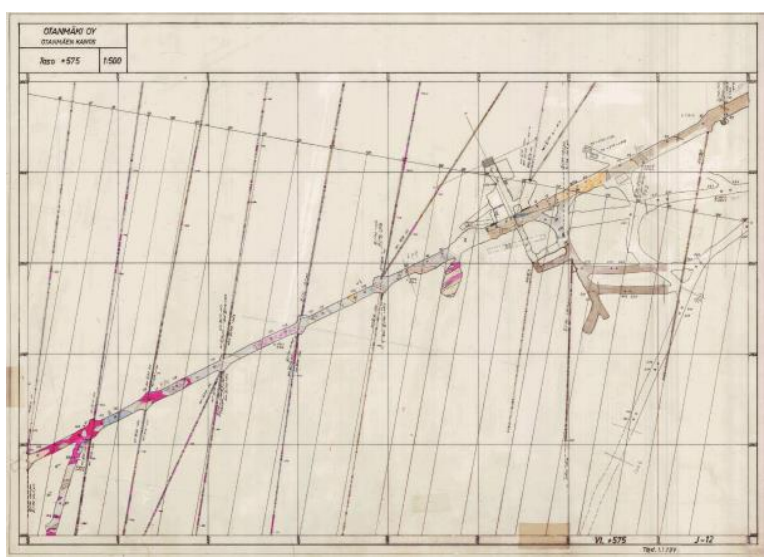

Figure 3. Historical map from level 575 Information included inter alia: old mine coordinates, KKJ coordinates, tunnels, previous ore bodies and exploration diamond drill holes

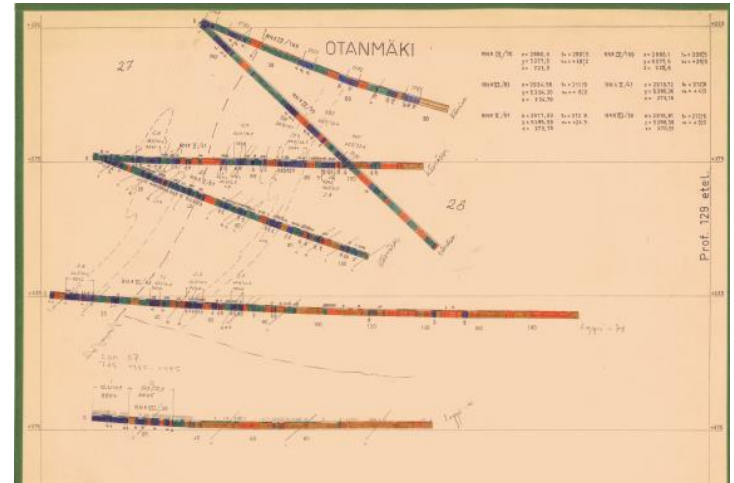

Figure 4. Historical map of exploration diamond drill holes, showing mineralized intersections, grades, as well as 3D location

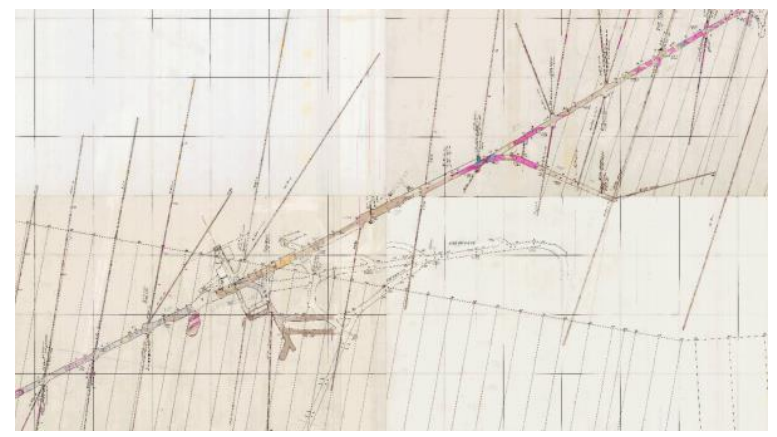

Figure 5. Stitching historical maps to a mosaic map and georeferencing - Mine level 575

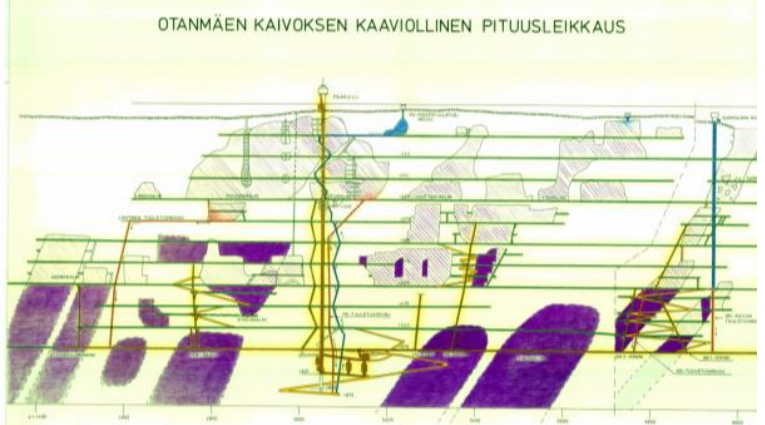

Figure 6. Historical map - cross section of the mine 


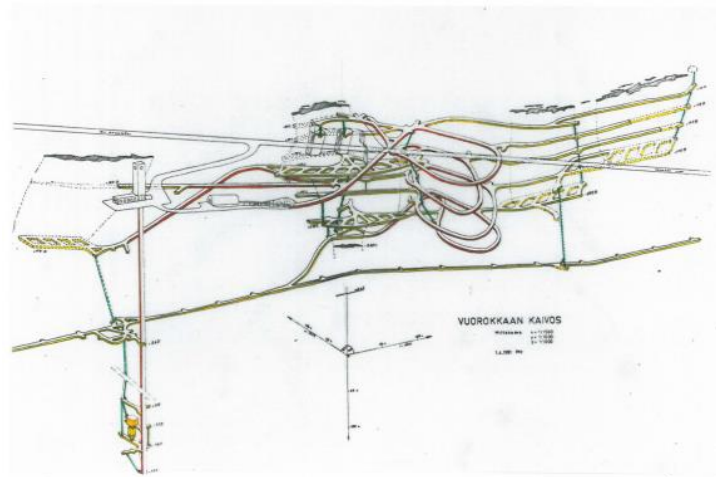

Figure 7. Historical isometric map - part of the old mine area near Otamäki Mine

\section{Results}

A 3D Digital Inventory Model for the Otamäki mine is in the process of being compiled using both historical data, which is being digitized and newly acquired rapid hand held laser scanning data.

The derived digital tunnel network model is presented on Figure 8 and 9. On Figure 8, we can see the main hoisting shaft in the middle and an auxiliary hoisting shaft on the left. On Figure 9, a preliminary view of the open pit area is presented.

Some problems were encountered when delineating inclined tunnels within the 3D model. The initial data were mostly horizontally aligned as 2D maps and some parts of the connecting tunnels between main levels had to be constructed manually.

Our rapid laser scanning experiments were a success. The whole hoisting tower was scanned under 1 hour 30 minutes. The measurement started on the ground floor, went up floor-by-floor and then descended back to the ground floor, where lastly, a small basement was measured. This measurement was undertaken as one continuous scan, so no referencing was needed.

However, a couple of problems were noticed. The most severe problem occurred because of the complexity of the building (Figures 10 and 11). The operator wasn't sure if he had scanned all the areas from the tower (he didn't); and he also wasn't sure if every corner and blind spot was covered (it wasn't). Complexity problems were made worse when the operator lost daylight after sunset. These holes in the scanning are easily recovered by making complementary measurements later on. It should be noted however, that results from hand held laser scanning are not instant, that they need cloud computing and possible holes in measurement data are noticed only after the operator has left the areas of interest.

The scanning of the evacuation shelter area (Figure
13) was straight forward. The whole process of collecting a 65 million-point cloud model took under one hour. The complexity within the shelter was simple and presented no difficulties. Two interesting areas were included to the scan: the first was a steep stairway decent at the entrance of the shelter (Figure 12); the second was a small area where the operator had to crawl through a small hole with a size of $40 \times 70 \mathrm{~cm}$ (Figure 14). The length of the shelter was approximately $170 \mathrm{~m}$ width between $3.1-6.0 \mathrm{~m}$ and height was around $3 \mathrm{~m}$.

Some results from surface reconstructions are presented in Figures 15 and 16.

Geological shells and tunnels within the inventory model are presented in Figure 17 and 18; and the mineral resource block model is shown on Figure 19. The digital database was imported, together with digitized ore maps into Surpac and mineralized body was modelled based on the historic drill logs and assay data.

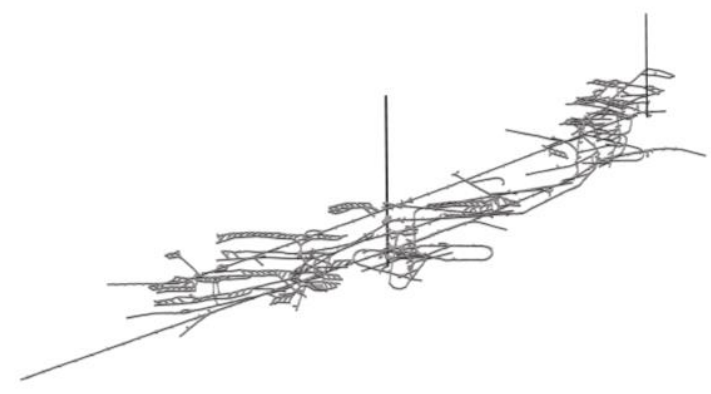

Figure 8. 3D model of the tunnel network 3D Digital Mine Inventory Model modelled from the historical 2D maps (Model constructed by Jouni Kankkunen from JK-Kaivossuunnitelu OY)

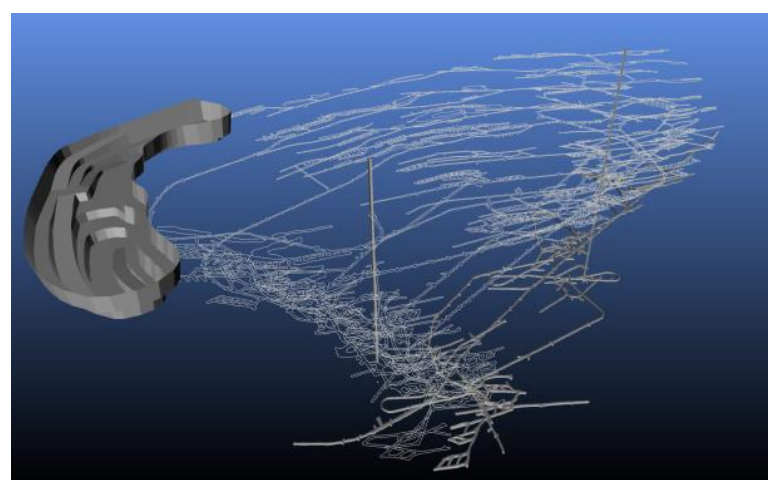

Figure 9. Model of open pit and the whole of the underground tunnel network (Model constructed by Jouni Kankkunen from JK-Kaivossuunnitelu $\mathrm{OY})$ 


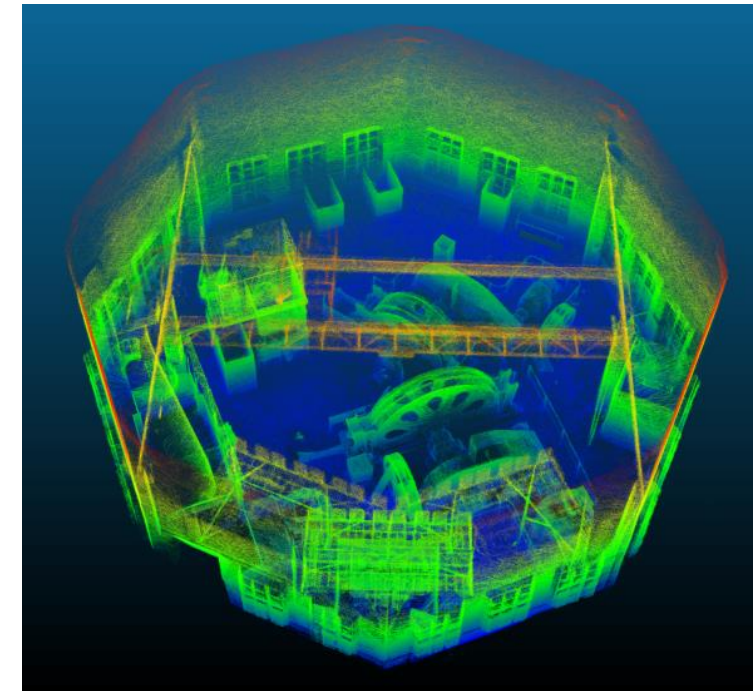

Figure 10. Rapid laser scanning results of the hoisting tower -8 th floor

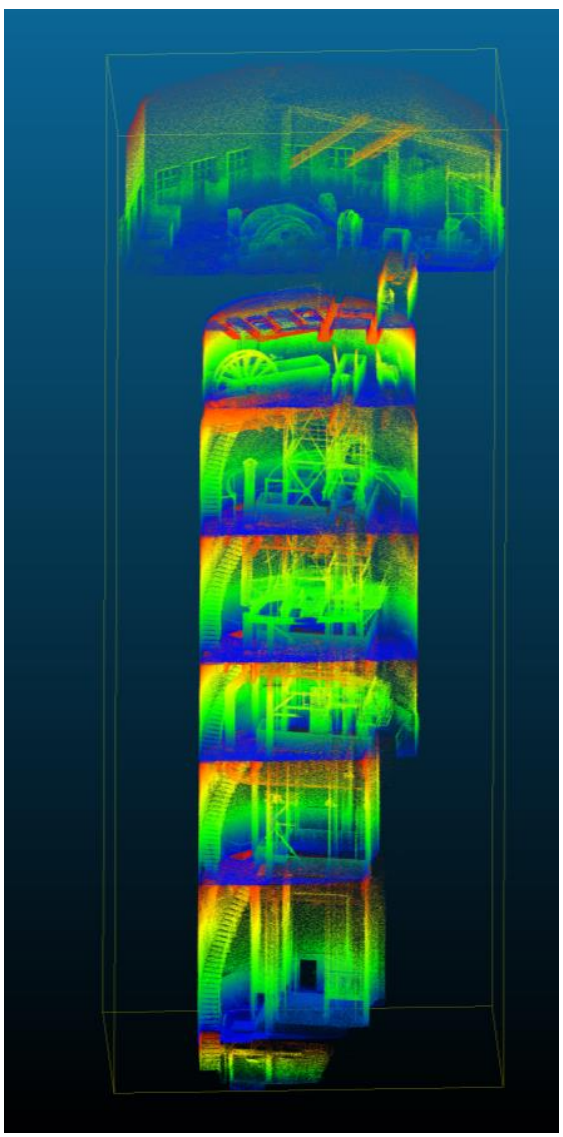

Figure 11. Rapid laser scanning results of the hoisting tower - Cross section of the whole tower

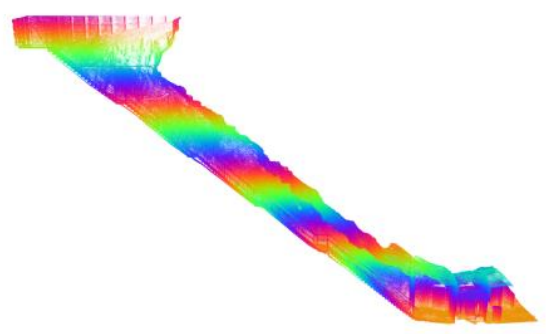

Figure 12. Rapid laser scanning results of the evacuation shelter - Cross-section of the steep entrance

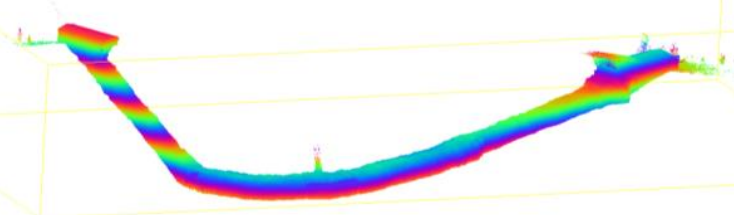

Figure 13. Rapid laser scanning results of the evacuation shelter - The whole shelter tunnel

Figure 14. Rapid laser scanning results of the evacuation shelter - Measurer had to crawl through a small hole in a wall while simultaneously scanning

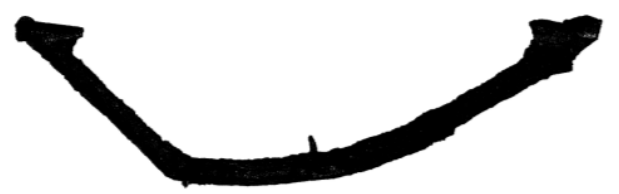

Figure 15. Rapid laser scanning results of the evacuation shelter - Point cloud converted to mesh: a dxf file with 50k faces 


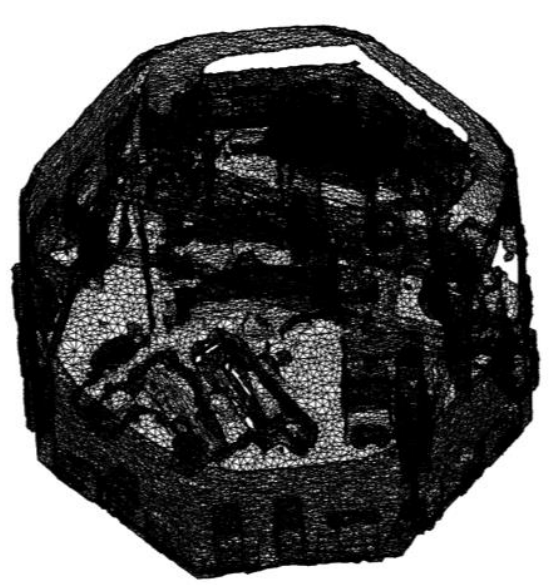

Figure 16. Rapid laser scanning results of the tower - Point cloud converted to mesh: a dxf file with $150 \mathrm{k}$ faces top floor

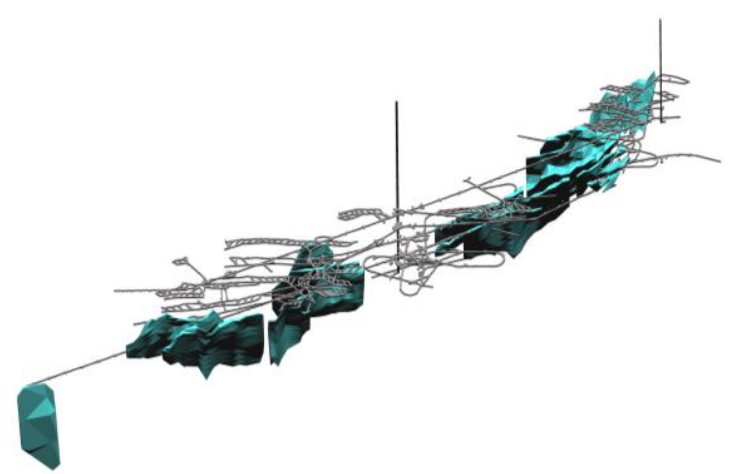

Figure 17. Part of the current 3D digital mine inventory model of Otamäki Mine - grade shells and tunnels (Model constructed by Jyrki Parkkinen, Geokonsultointi Parkkinen and Jouni Kankkunen, JK-Kaivossuunntelu Oy)

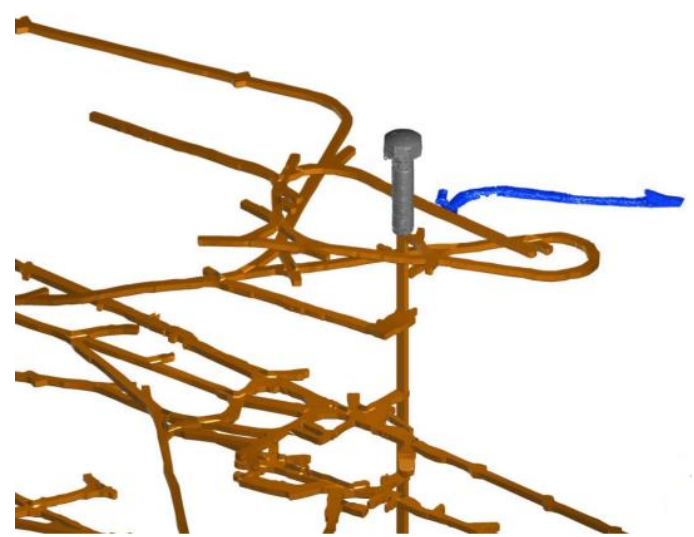

Figure 18. Part of the current 3D digital mine inventory model of Otamäki Mine - new rapid laser scanning data and tunnels from historical data (Surpac) (Screen capture by Juho Torvi, Kajaani university of applied sciences)

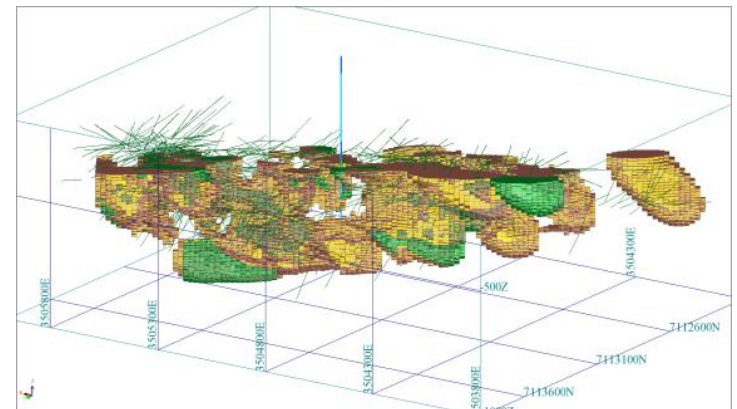

Figure 19. Part of the current Otamäki block model - Fe content study and drill holes (Model constructed by Jyrki Parkkinen, Geokonsultointi Parkkinen)

\section{Conclusion}

Rapid handheld laser scanning with simultaneous mapping and location is very fast method to scan and map infrastructure. We estimated that it would have taken two days to scan the whole hoisting tower using standard tripod laser scanning (including the planning phase) because such a cramped space full of equipment would make referencing hard, and also multiple scanning locations per floor would be needed. Handheld laser scanning for point clouds performed the task in less than 1.5 hours.

Our second laser scanning experiment of the evacuation shelter identified two interesting operational challenges: a) A small $40 \times 70 \mathrm{~cm}$ passage through which the operator had to crawl while simultaneously scanning; and b) A steep and cramped entrance inclined at approximately 43 degrees to the shelter.

In both cases the point cloud scanner produced visually satisfactory results. However, no reference or test measurements have yet been collected for comparison. Noisy data could be seen as a problem, especially when the point cloud is processed to triangulated surfaces. Screened Poisson surface reconstruction was the method chosen because it seemed to handle noise; however, the results still are not satisfactory and more work is needed in the area of surface reconstruction.

The current state of Otamäki Mine 3D digital inventory model has been discussed. Our workflow process for handling historical data (see Table 1.) has been presented; and the current 3D digital mine inventory model (including tunnels and ore body) is shown in Figure 17. However, at this stage the newly scanned handheld laser point cloud results have not been completely transformed into the mine 3D coordinate system precisely and should be done later on.

Traditionally, mine operators have set their own standards with respect to infrastructure and construction, and have had to overcome the challenges involved in 
integrating designs in a dynamic environment. But as the mining industry progresses towards the concept of the digital or intelligent mine, and the need for improved efficiencies, codes of practice such as YIV2014 Infra BIM (Infrastructure industry) and COBIM2012 (building industry) should result in common, verifiable and standardized methodologies and open specifications. Such methodologies and specifications would assist to process from 2D drawings and measured data, such as historic data from Otanmäki to a digital 3D mine inventory model The current open specifications for infrastructure and building industry give us two different reference platforms for developing a mining BIM . Adoption of BIM 3D digital approaches in the mining industry could assist in construction, dayto-day operations and management, mine closure and it would greatly assist if the mine was to re-opened at some time in the future for whatever reason.

\section{References}

[1] M. J. Brennan and E. S. Schwartz, "Evaluating Natural Resource Investments," J. Bus., vol. 58, no. 2, pp. 135-157, huhtikuu 1985.

[2] A. Moel and P. Tufano, "When Are Real Options Exercised? An Empirical Study of Mine Closings," Rev. Financ. Stud., vol. 15, no. 1, pp. 35-64, Jan. 2002.

[3] S. Shafiee, E. Topal, and M. Nehring, "Adjusted real option valuation to maximise mining project value-A case study Using Century Mine," in Project Evaluation Conference, 2009, pp. 125-134.

[4] S. A. Abdel Sabour, "Dynamics of threshold prices for optimal switches: the case of mining," Resour. Policy, vol. 27, no. 3, pp. 209-214, syyskuu 2001.

[5] "Yleiset inframallivaatimukset 2014 - YIV 2014 InfraBIM" [Online]. Available at: http://www.infrabim.fi/yiv2014/

[6] “COBIM 2012 | buildingSMART Finland." [Online]. Available at: http://www.en.buildingsmart.kotisivukone.com/3.

[7] "QGIS." [Online]. Available at: http://www.qgis.org/.

[8] "KKJ / Finland Uniform Coordinate System: EPSG Projection -- Spatial Reference." [Online]. Available http://spatialreference.org/ref/epsg/kkj-finlanduniform-coordinate-system/.
[9] M. Bosse, R. Zlot, and P. Flick, "Zebedee: Design of a Spring-Mounted 3-D Range Sensor with Application to Mobile Mapping," IEEE Trans. Robot., vol. 28, no. 5, pp. 1104-1119, lokakuu 2012.

[10] M. Bosse and R. Zlot, "Place recognition using keypoint voting in large 3D lidar datasets," in 2013 IEEE International Conference on Robotics and Automation (ICRA), 2013, pp. 2677-2684.

[11] A. Nüchter, 3D Robotic Mapping: The Simultaneous Localization and Mapping Problem with Six Degrees of Freedom. Springer Science \& Business Media, 2009.

[12] M. Kazhdan and H. Hoppe, "Screened Poisson surface reconstruction," ACM Trans. Graph. TOG, vol. 32, no. 3, p. 29, 2013.

[13] I. M. Glacken and D. V. Snowden, "Mineral resource estimation," Miner. Resour. Ore Reserve Estim. AusIMM Guide Good Pract. Australasian. Inst. Min. Metall. Melb. pp. 189-198, 2001.

[14] The JORC Code: Australasian Code for Reporting of Exploration Results, Minerals Resources and Ore Reserves.2012 edition. [Online] available at, http://www.jorc.org/docs/jorc_code2012.pdf

[15] Standards of Disclosure for Mineral Projects. [Online] available at, http://web.cim.org/standards/documents/Block484 _Doc111.pdf 